\title{
Assessment of Process Parameters Influencing Delamination Factor on the Drilling of CFRC Composite Material with TiN Coated Carbide Tool
}

\author{
K. V. Krishna Sastry ${ }^{1 *}$, V. Seshagiri Rao ${ }^{2}$, K. Palanikumar ${ }^{3}$, R. Dhanalakshmi ${ }^{4}$ and Abhishek Kuravi ${ }^{5}$ \\ 'Research Scholar, Sathyabama University \& Professor in Mechanical Engineering, AVIT, Chennai, \\ India; kvkrishnasastry@gmail.com \\ ${ }^{2}$ Professor in Mechanical Engineering, St. Joseph's College of Engineering, Chennai, India; \\ Raosvaddi@hotmail.com \\ 3Principal, Srisairam Institute of Technology, Chennai, India; palanikumar_k@yahoo.com \\ ${ }^{4}$ Scientist, Transmission Division, CVRDE, Chennai, India; dlakshmi_2000@yahoo.com \\ 5University of Texas, Austin, U.S.A; abhikuravi@yahoo.co.in
}

\begin{abstract}
Carbon Fibre Reinforced Carbon (CFRC) Composite material is highly used in advanced industrial sector, especially in manufacturing of space shuttles and other expensive aerospace categories. The material's significant position and its growing importance has created interest among research community about the machining technology of this special material. This paper aims at finding the experimental drilling characteristics values of $\mathrm{C}$-C composite by the combination of Taguchi method and Grey theory Technique. Manufacturing of good quality products at lower cost is the main objective of the modern industrial sector, and this is obtained by using optimal methods to the manufacturing conditions. This paper discusses about the use of Grey Theory to find the optimum drilling values. The experiments were conducted by using a Titanium Nitride coated Carbide drill tool on a carbon-carbon composite material plate with CNC Drilling Machine. This paper explains and demonstrates the influence of optimal set of characteristics, such as Spindle speed, Feed and Tool angle on the Delamination factors.
\end{abstract}

Keywords: CFRC, C-C Composites, CorelDraw, Delamination, GRA, RCC, Taguchi Method

\section{Introduction}

Drilling is the process of production of holes by removing the material with the help of a tool called drill bit. It is a frequently used machining process and also commonly used final operation in assembly of the advanced structures. Therefore, any damage that leads to the rejection of parts represents an expensive loss. Drilled holes are characterized by their sharp edge on the entrance side and the presence of burrs on the exit side. The ubiquitous twist drill bits, used in metalworking also work well in composite material, but they tend to chip that out at the Entry and Exit of the hole $e^{1}$. Generally, Drilling is a complicated operation and it becomes more complicated if the material is a composite one. Delamination of fibres is the major damage, generally occurring in drilling of composite materials. For example, in the aircraft industry, drilling associated delamination accounts for $60 \%$ of all part rejections during final assembly of an aircraft ${ }^{2}$. Hence, productions of quality holes require the selection of suitable parameters. The quality of product, generally, depends upon the process parameters. Optimal methods play vital role in choosing the controlling parameters and further enhancing the quality of the product ${ }^{3}$. 


\section{Carbon-Carbon Composite Materials}

The Carbon-Carbon composite materials, which are nothing but Carbon Fibre Reinforced Carbon Composites (CFRC), are the logical materials for the production of emerging structures like space shuttles, missiles, launching vehicles, advanced defence items, aircraft brakes, racing car brakes, prosthetic devices and other bio materials. These materials are also popularly called as Reinforced Carbon-Carbon (RCC) composite materials. In this composite material, The Carbon fibres are reinforced in to a Carbon matrix. The SEM image of the composition of this unique material is shown in Figure 1. The EDAX Graph and Table reveal that the Carbon element constitutes a major portion of the composite material i.e. $98.77 \%$ by atomic structure and $96.58 \%$ by weight.

These composites have light weight, high strength and high thermal stability properties. For example, CVRDE and DRDO organizations have developed high performance brake discs for Main Battle Tank Arjun. The weight of brake discs was compared with that of steel material, which is used to fabricate the brake discs and found a saving of weight by $75 \%{ }^{4}$. Nizam orthopedic Centre, Hyderabad has used this advanced material calipers to heavy metallic calipers, which reduced the weight of calipers to one tenth of its original weight ${ }^{5-7}$.

\section{Grey Relational Analysis}

Mr. Deng has developed a theory called Grey theory, which provides an efficient solution to uncertain, multi input, incomplete and discrete data problems. In this, optimization of the complicated multiple process responses can be converted in to a single grey relational grade and the highest grey relational grade gives the factor level optimization ${ }^{8}$. Krishnasastry have carried out the grey theory analysis on CFRC composites drilling process with various drill bits of different materials and different twist angles ${ }^{8}$.

This paper's objective is to find the optimal levels of controlling parameters for drilling of Carbon-Carbon (C/C) composite materials. Deng's Grey Relational Analysis was applied to obtain the optimum values of process parameters.

\section{Literature Survey}

Very less or no literature is available on the drilling of C-C composites. A lot of research is done on drilling of various composite materials. Even literature is available on the drilling of Carbon Fibre Reinforced Polymer (CFRP) composites but not on the drilling of CFRC composites. George et al. determined the Turning parameters of carbon-carbon composites on EDM machine 9 . J.R Ferreira have carried out various tests on rocket nozzle throats to determine the influence of different tool parameters ${ }^{10}$.

\section{Experimental Investigation of Drilling Parameters of CFRC}

Due to the non-availability of information on the drilling process of CFRC composite material, it is decided to
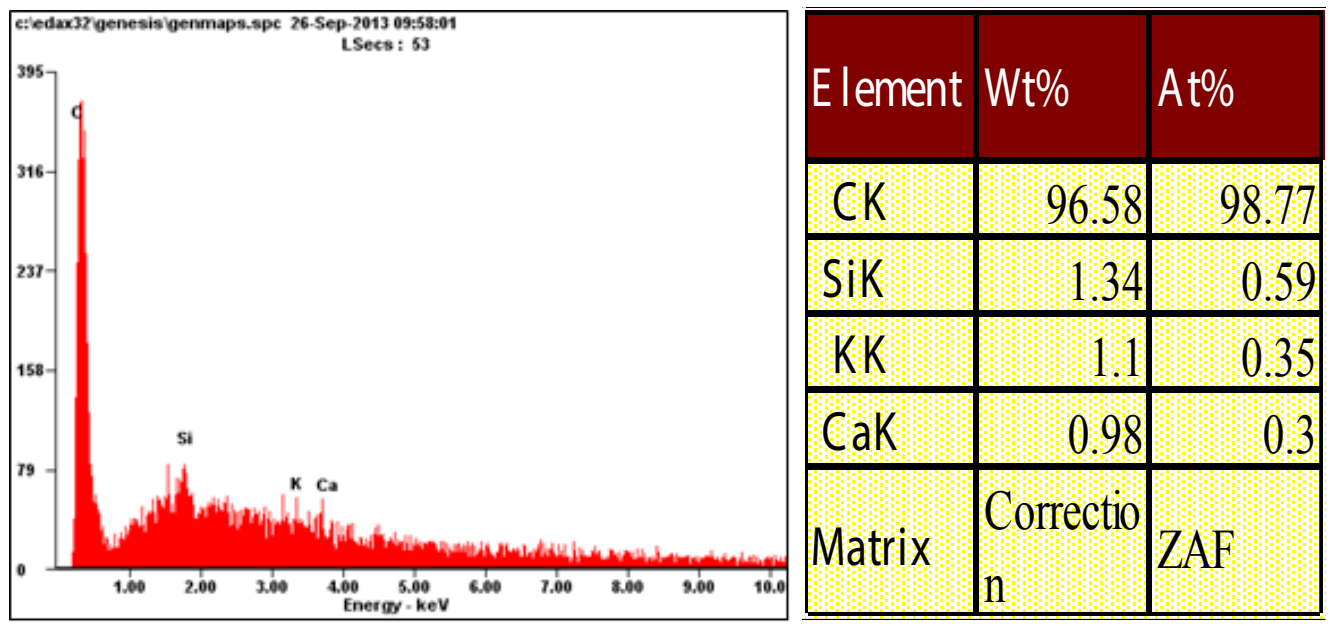

Figure 1. Composition of CFRC composite material (edax graph and edax table). 
investigate the impact of process parameters by conducting an experiment on this ubiquitous material. The Drilling process tests were conducted on a $\mathrm{CNC}$ machine, VMC100 which was developed by ARIX CNC MACHINE Co. Ltd, Taiwan. The experiments were conducted at the Anna University, Chennai Premises. A Titanium nitride coated carbide drill bit of $10 \mathrm{~mm}$ diameter is used for drilling of carbon-carbon composite material plate. The experimental setup is shown in Figure 2 and the material used for experiment is shown in Figure 3.

In drilling, the movement and speed of the multipoint cutting tool is specified by various parameters. These include the selection of tool geometry, tool material, work material etc. In this test, Point Angle, Feed rate and Spindle speed were chosen as the three control factors and each factor was designed to have three levels shown in Table 1.

1. Point angle: It is defined as the twist angle of the tip of the drill tool and is measured in degrees $\left(^{\circ}\right)$.

2. Spindle Speed: It is defined as the spindle's rotational speed in rpm i.e. Revolutions per minute.

3. Feed: It is defined as the speed of the cutting tool's movement relative to the work piece as the tool makes a cut. It is specified in millimeter/minute $(\mathrm{mm} / \mathrm{min})$.

Table 1. Process parameters and their levels

\begin{tabular}{lccc}
\hline $\begin{array}{l}\text { Drilling } \\
\text { Parameters }\end{array}$ & Point Angle & Spindle Speed & Feed Rate \\
\hline Symbol & A & N & F \\
Unit & $\left({ }^{0}\right)$ & r.p.m & $\mathrm{mm} / \mathrm{min}$ \\
Level (1) & 135 & 1000 & 100 \\
Level (2) & 100 & 3000 & 300 \\
Level (3) & 118 & 2000 & 500 \\
\hline
\end{tabular}

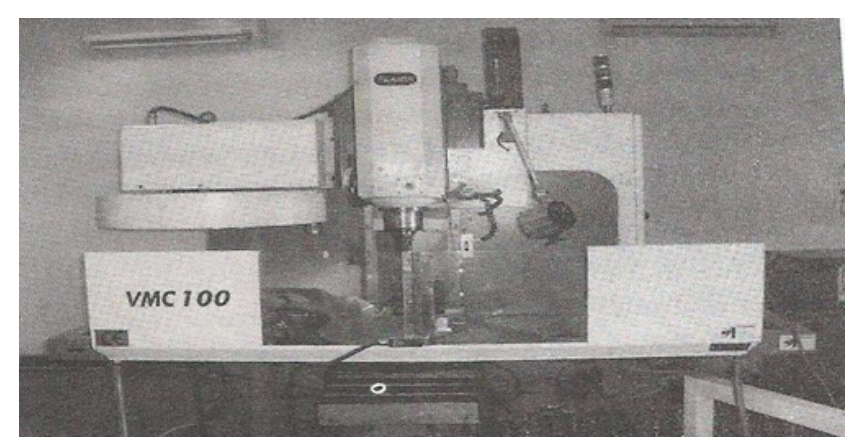

Figure 2. Experimental setup.
According to the Taguchi's method of quality design, it is decided to conduct experiments using $\mathrm{L}_{27}$ orthogonal array table. This reduces the experiments number ${ }^{11}$. The $\mathrm{L}_{27}$ Orthogonal array is shown Table 2 .

\section{Measurement of Delamination}

The failure mode in fibre reinforced composites is known as Delamination. It is the process of separation of layers in a laminate. It is among the most serious concerns during drilling of composite materials, while the evaluation of the drilling induced delamination damage in material is rather difficulty, particularly for the carbon fibre based composites. To minimize the delamination damage, the drilling performance is evaluated by the two Delamination Factors both at entry and exit sides of the hole. The image of delamination in CFRC is shown in Figure 4. This photograph is taken through Scanning Electron Microscope (SEM) at IIT, Chennai.

A. Delamination Factor $\left\{D_{f}\right\}$. It is the degree of Delamination. It is defined as the ratio between the diameter $\mathrm{D}_{\max }$, i.e. the greatest dia between the centre and a point located on the max.extent of the defect and $\mathrm{D}$ i.e. the nominal dia $^{12}$. The extensive damage of drilling occurs due to peel-up and push-out effects respectively are close to the entry and exit of the hole ${ }^{13}$.

Determination of Delamination Factors: These are measured by a method known as imaging method, which is inexpensive in nature. The photographs of the drilled holes are taken by using a digital camera and the measurement of both diameters i.e. $\mathrm{D}_{\max }$ and $\mathrm{D}$ are done with the help of an image software known as, Corel DRAW X5. The procedure is shown in Figure 5. By using the above mentioned formulae i.e. $\mathrm{D}_{\max } / \mathrm{D}$, the delamination factors are calculated. These values are determined for all

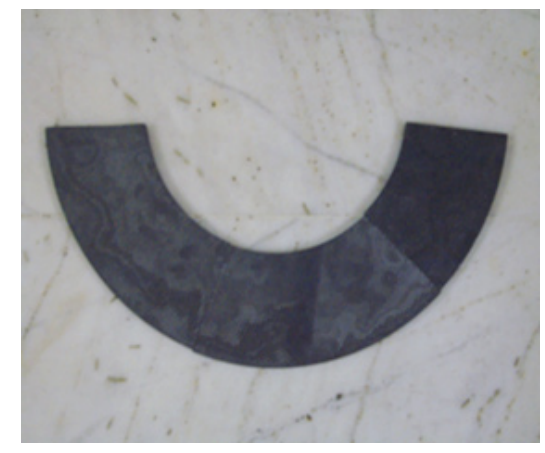

Figure 3. C-C material. 


\section{K. V. Krishna Sastry, V. Seshagiri Rao, K. Palanikumar, R. Dhanalakshmi and Abhishek Kuravi}

Table 2. A model of L27orthogonal array

\begin{tabular}{|c|c|c|c|c|c|c|c|c|c|c|c|c|c|}
\hline Experiment & $\mathrm{P} 1$ & P2 & P3 & $\mathrm{P} 4$ & P5 & P6 & P7 & P8 & P9 & P10 & $\mathrm{P} 11$ & P12 & $\mathrm{P} 13$ \\
\hline 1 & 1 & 1 & 1 & 1 & 1 & 1 & 1 & 1 & 1 & 1 & 1 & 1 & 1 \\
\hline 2 & 1 & 1 & 1 & 1 & 2 & 2 & 2 & 2 & 2 & 2 & 2 & 2 & 2 \\
\hline 3 & 1 & 1 & 1 & 1 & 3 & 3 & 3 & 3 & 3 & 3 & 3 & 3 & 3 \\
\hline 4 & 1 & 2 & 2 & 2 & 1 & 1 & 1 & 2 & 2 & 2 & 3 & 3 & 3 \\
\hline 5 & 1 & 2 & 2 & 2 & 2 & 2 & 2 & 3 & 3 & 3 & 1 & 1 & 1 \\
\hline 6 & 1 & 2 & 2 & 2 & 3 & 3 & 3 & 1 & 1 & 1 & 2 & 2 & 2 \\
\hline 7 & 1 & 3 & 3 & 3 & 1 & 1 & 1 & 3 & 3 & 3 & 2 & 2 & 2 \\
\hline 8 & 1 & 3 & 3 & 3 & 2 & 2 & 2 & 1 & 1 & 1 & 3 & 3 & 3 \\
\hline 9 & 1 & 3 & 3 & 3 & 3 & 3 & 3 & 2 & 2 & 2 & 1 & 1 & 1 \\
\hline 10 & 2 & 1 & 2 & 3 & 1 & 2 & 3 & 1 & 2 & 3 & 1 & 2 & 3 \\
\hline 11 & 2 & 1 & 2 & 3 & 2 & 3 & 1 & 2 & 3 & 1 & 2 & 3 & 1 \\
\hline 12 & 2 & 1 & 2 & 3 & 3 & 1 & 2 & 3 & 1 & 2 & 3 & 1 & 2 \\
\hline 13 & 2 & 2 & 3 & 1 & 1 & 2 & 3 & 2 & 3 & 1 & 3 & 1 & 2 \\
\hline 14 & 2 & 2 & 3 & 1 & 2 & 3 & 1 & 3 & 1 & 2 & 1 & 2 & 3 \\
\hline 15 & 2 & 2 & 3 & 1 & 3 & 1 & 2 & 1 & 2 & 3 & 2 & 3 & 1 \\
\hline 16 & 2 & 3 & 1 & 2 & 1 & 2 & 3 & 3 & 1 & 2 & 2 & 3 & 1 \\
\hline 17 & 2 & 3 & 1 & 2 & 2 & 3 & 1 & 1 & 2 & 3 & 3 & 1 & 2 \\
\hline 18 & 2 & 3 & 1 & 2 & 3 & 1 & 2 & 2 & 3 & 1 & 1 & 2 & 3 \\
\hline 19 & 3 & 1 & 3 & 2 & 1 & 3 & 2 & 1 & 3 & 2 & 1 & 3 & 2 \\
\hline 20 & 3 & 1 & 3 & 2 & 2 & 1 & 3 & 2 & 2 & 2 & 2 & 1 & 3 \\
\hline 21 & 3 & 1 & 3 & 2 & 3 & 2 & 1 & 3 & 3 & 1 & 3 & 2 & 1 \\
\hline 22 & 3 & 2 & 1 & 3 & 1 & 3 & 2 & 2 & 1 & 3 & 3 & 2 & 1 \\
\hline 23 & 3 & 2 & 1 & 3 & 2 & 1 & 3 & 3 & 2 & 1 & 1 & 3 & 2 \\
\hline 24 & 3 & 2 & 1 & 3 & 3 & 2 & 1 & 1 & 3 & 2 & 2 & 1 & 3 \\
\hline 25 & 3 & 3 & 2 & 1 & 1 & 3 & 2 & 3 & 2 & 1 & 2 & 1 & 3 \\
\hline 26 & 3 & 3 & 2 & 1 & 2 & 3 & 2 & 3 & 3 & 2 & 3 & 2 & 1 \\
\hline 27 & 3 & 3 & 2 & 1 & 3 & 2 & 1 & 2 & 1 & 3 & 1 & 3 & 2 \\
\hline
\end{tabular}

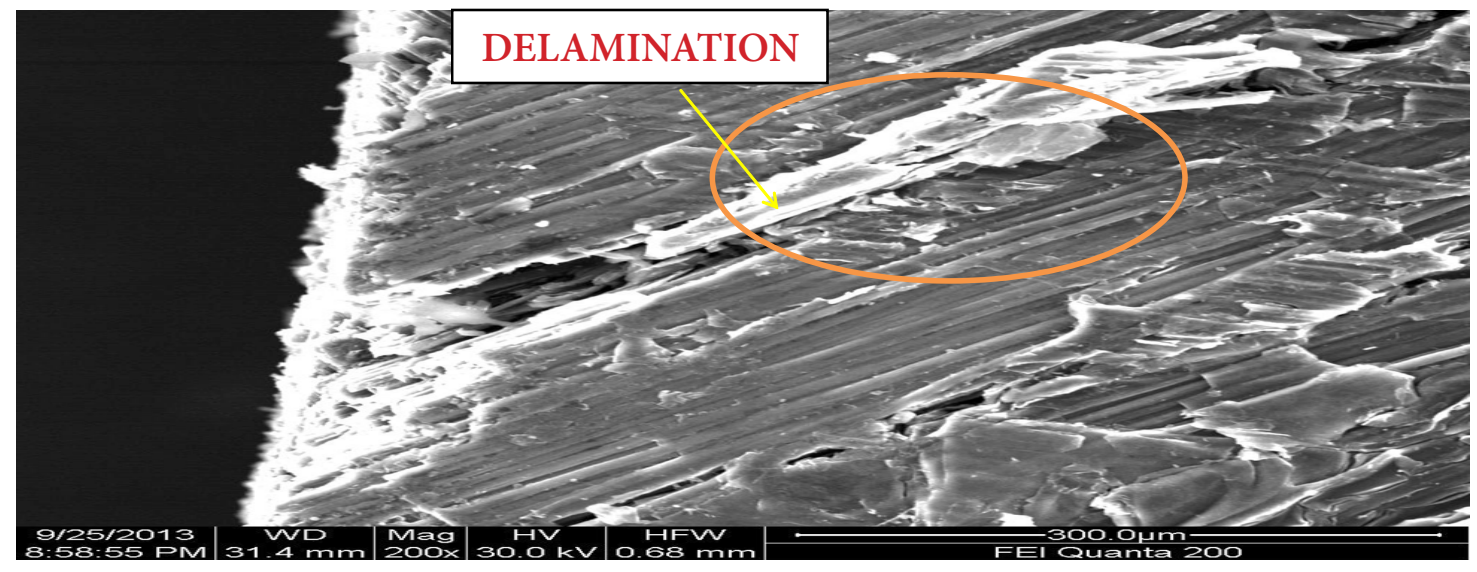

Figure 4. SEM image of delamination. 


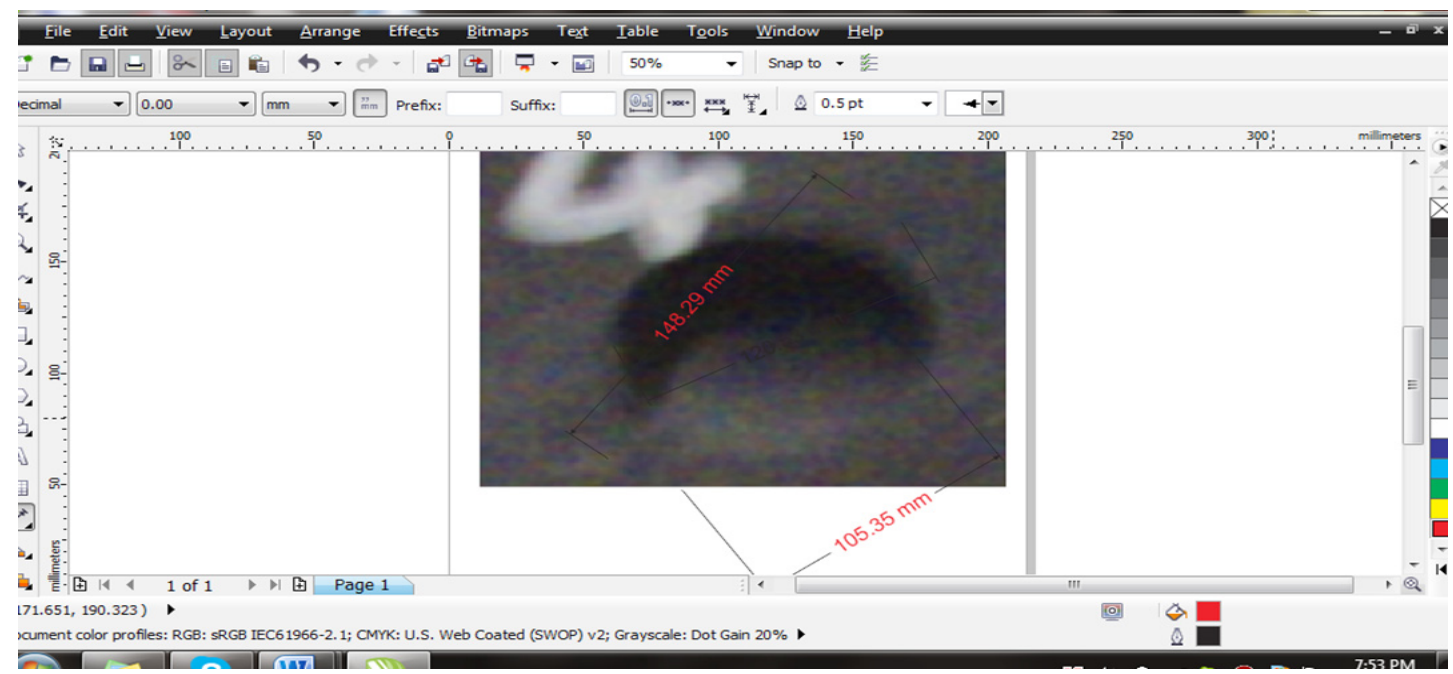

Figure 5. Calculation of diameters.

27 holes on both sides in the same manner and entered. The delamination factor values are also represented in the Graph i.e. Figure 6.

The experimental values of response parameters i.e. the values of delamination factors, which are calculated by using the above mentioned software, are entered in Table 3.

\section{Data Preprocessing of Performance Parameters}

Data Pre-Processing is nothing but normalization of Data. It is transferring the original sequence to a comparable sequence and this is necessary, when the range and unit in one data sequence may vary with others. It is also required when the sequence scatter range is too big.

If the target value is infinite for the original series, then the normalized value is taken for "larger-the-better" characteristic and it is expressed as,

$$
x_{i}^{*}(k)=\frac{x_{i}^{0}(k)-\min x_{i}^{0}(k)}{\max x_{i}^{0}(k)-\min x_{i}^{o}(k)}
$$

The normalized value of "lower-the-better characteristic is expressed as,

$$
x_{i}^{*}(k)=\frac{\max x_{i}^{0}(k)-x_{i}^{0}(k)}{\max x_{i}^{0}(k)-\min x_{i}^{0}(k)}
$$

If the characteristic is "nominal-the-best", then the normalized value is expressed as

$$
x_{i}^{*}(k)=1-\frac{\left|x_{i}^{0}(k)-x^{0}\right|}{\max x_{i}^{0}(k)-x^{0}}
$$

Where $\mathrm{i}=1 \ldots \mathrm{m} ; \mathrm{k}=1 \ldots \mathrm{n} . \mathrm{m}$ is the number of experimental data items and $\mathrm{n}$ is the number of parameters. $x_{i}^{0}(k)$ is the original sequence, $x_{i}^{*}(k)$ is the sequence after the normalization, $\max x_{i}^{0}(k)$ is the largest value and $\min x_{i}^{0}(k)$ is the smallest value of $x_{i}^{0}(k)$ and $\mathrm{x}^{0}$ is the desired target value $e^{4,8}$.

The data preprocessing results of delamination factors are calculated by using equation 3 , as the performance characteristics are to be minimized.

\section{Calculation of GRC and GRG}

The Grey Relational Coefficient (GRC) is calculated for all trials after completion of normalization of data. The GRC gives the relationship between the ideal and real normalized experimental values. The Grey Relational Coefficient, $\xi_{\mathrm{ij}}$ is calculated by using the following formula,

$$
\xi_{\mathrm{ij}=}\left\{\Delta_{\min }+\zeta \Delta_{\max }\right\} /\left\{\left|\mathrm{x}_{\mathrm{i}}^{0}-\mathrm{x}_{\mathrm{ij}}\right|+\zeta \Delta_{\max }\right\}
$$

where, $\mathrm{x}_{\mathrm{i}}{ }^{\circ}$ is the ideal normalized value for the $\mathrm{i}^{\text {th }}$ performance parameter and $\zeta$ is a special coefficient and $\zeta$ is taken as 0.5 .

The data of GRCs can be reduced to a single value and is known Grey Relational Grade (GRG). The GRG is calculated by using the formula GRG $\left(\alpha_{j}\right)=\frac{1}{N} \sum_{i=1}^{N} \xi_{i j}$ 
Table 3. Delamination Factor Values

\begin{tabular}{|c|c|c|c|c|c|}
\hline Expt. No. & $\begin{array}{l}\text { Point Angle, } \\
\mathrm{A}\left({ }^{0}\right)\end{array}$ & $\begin{array}{l}\text { Spindle Speed } \\
\text { N(rpm) }\end{array}$ & $\begin{array}{l}\text { Feed rate } \\
\mathrm{F}(\mathrm{mm} / \mathrm{min})\end{array}$ & Entry Delamination factor $D_{f 1}$ & Exit Delamination Factor $\mathrm{D}_{\mathrm{f} 2}$ \\
\hline 1 & 135 & 1000 & 100 & 1.050276 & 1.024774 \\
\hline 2 & 135 & 1000 & 300 & 1.012348 & 1.009166 \\
\hline 3 & 135 & 1000 & 500 & 1.045766 & 1.024774 \\
\hline 4 & 135 & 3000 & 100 & 1.091755 & 1.044849 \\
\hline 5 & 135 & 3000 & 300 & 1.001879 & 1.035635 \\
\hline 6 & 135 & 3000 & 500 & 1.01718 & 1.007137 \\
\hline 7 & 135 & 2000 & 100 & 1.009983 & 1 \\
\hline 8 & 135 & 2000 & 300 & 1.015939 & 1.013881 \\
\hline 9 & 135 & 2000 & 500 & 1.054045 & 1.006704 \\
\hline 10 & 100 & 1000 & 100 & 1.013508 & 1.013228 \\
\hline 11 & 100 & 1000 & 300 & 1.01951 & 1.033258 \\
\hline 12 & 100 & 1000 & 500 & 1.064578 & 1.01753 \\
\hline 13 & 100 & 3000 & 100 & 1.009156 & 1.034754 \\
\hline 14 & 100 & 3000 & 300 & 1.02375 & 1.04234 \\
\hline 15 & 100 & 3000 & 500 & 1.019844 & 1.008397 \\
\hline 16 & 100 & 2000 & 100 & 1.075521 & 1.01708 \\
\hline 17 & 100 & 2000 & 300 & 1.016629 & 1.044606 \\
\hline 18 & 100 & 2000 & 500 & 1.079932 & 1.065364 \\
\hline 19 & 118 & 1000 & 100 & 1.066515 & 1.016654 \\
\hline 20 & 118 & 1000 & 300 & 1.025953 & 1.043824 \\
\hline 21 & 118 & 1000 & 500 & 1.022189 & 1.043824 \\
\hline 22 & 118 & 3000 & 100 & 1.006795 & 1 \\
\hline 23 & 118 & 3000 & 300 & 1.000373 & 1.045007 \\
\hline 24 & 118 & 3000 & 500 & 1.043323 & 1.108999 \\
\hline 25 & 118 & 2000 & 100 & 1.022899 & 1.044606 \\
\hline 26 & 118 & 2000 & 300 & 1.015639 & 1 \\
\hline 27 & 118 & 2000 & 500 & 1.001659 & 1.043824 \\
\hline
\end{tabular}

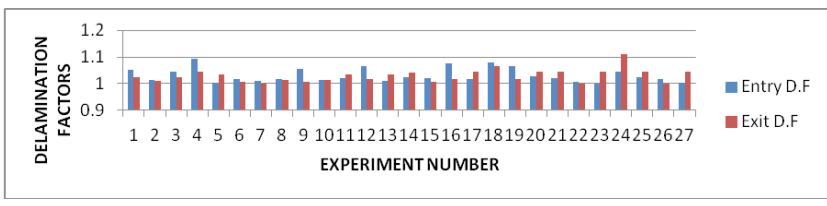

Figure 6. Delamination values.

The Normalized values, The GRC values and the GRG values for all experiments are given in Table 4. The Grade values are presented in the graph, vide Figure. 7. The calculated highest grade from the above expression will give the optimal combination of control factors i.e. $22^{\text {nd }}$ experiment.

\section{Result Analysis by using Response Table and Response Graph}

Since the design of experiment is based on an orthogonal array, it is possible to separate out the influence of each factor on the grade at different levels. The average grade for each level of inputs can be calculated entered in the Table 5. The graph is shown in Figure 8.

It is clearly understood from the response table and graphs that the control factors drill bit point angle at level 1 , spindle speed at level 2 and feed at level 2 is the optimal 
Table 4. Normalized values, GRC'S \& GRD

\begin{tabular}{llllcc}
\hline Expt.No. & \multicolumn{2}{c}{ Normalized Values } & Grey Relational Coefficients & GRADE \\
\hline 1. & 0.453905 & 0.77271 & 0.477968 & 0.687483 & 0.582726 \\
2. & 0.86896 & 0.915903 & 0.792343 & 0.856022 & 0.824182 \\
3. & 0.50326 & 0.77271 & 0.501635 & 0.687483 & 0.594559 \\
4. & 0 & 0.588539 & 0.333333 & 0.54857 & 0.440952 \\
5. & 0.983518 & 0.673072 & 0.968088 & 0.604648 & 0.786368 \\
6. & 0.81608 & 0.934522 & 0.73108 & 0.884208 & 0.807644 \\
7. & 0.894838 & 1 & 0.826225 & 1 & 0.913112 \\
8. & 0.82966 & 0.872652 & 0.74589 & 0.797006 & 0.771448 \\
9. & 0.41267 & 0.938497 & 0.459842 & 0.890468 & 0.675155 \\
10. & 0.85626 & 0.878645 & 0.776711 & 0.804693 & 0.790702 \\
11. & 0.790579 & 0.69488 & 0.7048 & 0.621025 & 0.662913 \\
12. & 0.297399 & 0.839177 & 0.415766 & 0.756632 & 0.586199 \\
13. & 0.903884 & 0.681148 & 0.838762 & 0.610611 & 0.724687 \\
14. & 0.744182 & 0.61156 & 0.661535 & 0.562784 & 0.61216 \\
15. & 0.786934 & 0.922964 & 0.701197 & 0.866497 & 0.783847 \\
16. & 0.177646 & 0.843297 & 0.378114 & 0.761379 & 0.569746 \\
17. & 0.822112 & 0.590768 & 0.737585 & 0.549914 & 0.64375 \\
18. & 0.129381 & 0.400326 & 0.364799 & 0.45468 & 0.409739 \\
19. & 0.276198 & 0.847211 & 0.408563 & 0.765945 & 0.587254 \\
20. & 0.720083 & 0.597941 & 0.641094 & 0.554288 & 0.597691 \\
21. & 0.761269 & 0.597941 & 0.676837 & 0.554288 & 0.615562 \\
22. & 0.929727 & 1 & 0.876773 & 1 & 0.938387 \\
23. & 1 & 0.587084 & 1 & 0.547695 & 0.773848 \\
24. & 0.53 & 0 & 0.515464 & 0.333333 & 0.424399 \\
25. & 0.753494 & 0.590768 & 0.669787 & 0.549914 & 0.609851 \\
26. & 0.832946 & 1 & 0.749564 & 1 & 0.874782 \\
27. & 0.985925 & 0.597941 & 0.972622 & 0.554288 & 0.763455 \\
\hline & & & & &
\end{tabular}

Table 5. Response table of grades

\begin{tabular}{lcccl}
\hline \multirow{2}{*}{ Control Factor } & \multirow{2}{*}{ Symbol } & \multicolumn{3}{c}{ GRG } \\
\cline { 3 - 5 } & & \multicolumn{1}{c}{ Level 1 } & \multicolumn{1}{c}{ Level 2 } & \multicolumn{1}{c}{ Level 3 } \\
\hline Drill bit Point Angle & $\mathrm{A}$ & 0.710682839 & 0.657304116 & 0.687247423 \\
Spindle Speed & $\mathrm{N}$ & 0.649087522 & 0.69914322 & 0.69233756 \\
Feed & $\mathrm{F}$ & 0.684157326 & 0.727460035 & 0.62895094 \\
\hline
\end{tabular}

Overall mean of Grey Relational Grade $=\mathbf{0 . 6 8 1 8 1 8 9 9 8}$

Table 6. Comparison of the predicted and the actual drilling parameters

\begin{tabular}{llll}
\hline \multirow{2}{*}{ Setting Level } & \multirow{2}{*}{ Initial Drilling Parameters } & \multicolumn{2}{c}{ Optimal Drilling Parameters } \\
\cline { 3 - 4 } & & $\mathrm{A}_{1} \mathrm{~N}_{2} \mathrm{~F}_{2}$ & $\mathrm{~A}_{3} \mathrm{~N}_{2} \mathrm{~F}_{1}$ \\
\hline Response & $\mathrm{F}_{3}$ & 1.045766 & 1.006795 \\
$\begin{array}{l}\text { Entry Delamination } \\
\text { factor Df }\end{array}$ & 1.079932 & & \\
Exit Delamination & 1.065364 & 1.035635 & 1 \\
Factor Df & & & \\
G R Grade & 0.409739 & 0.773648098 & 0.938387 \\
\hline
\end{tabular}




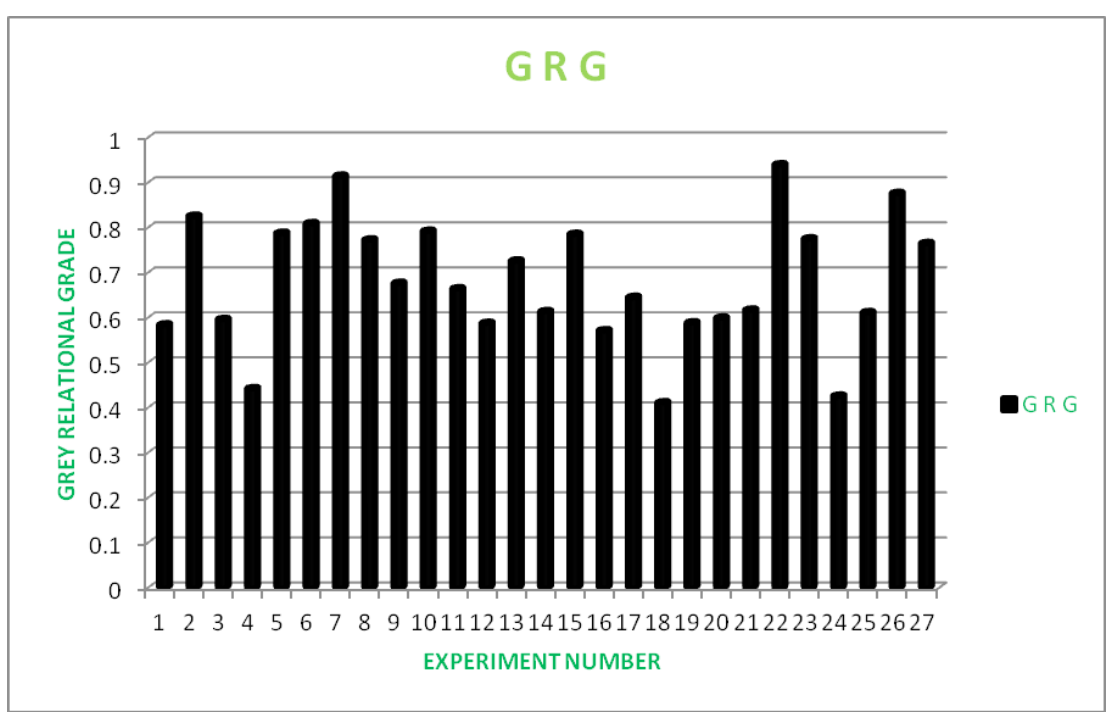

Figure 7. Grey relational grades values.

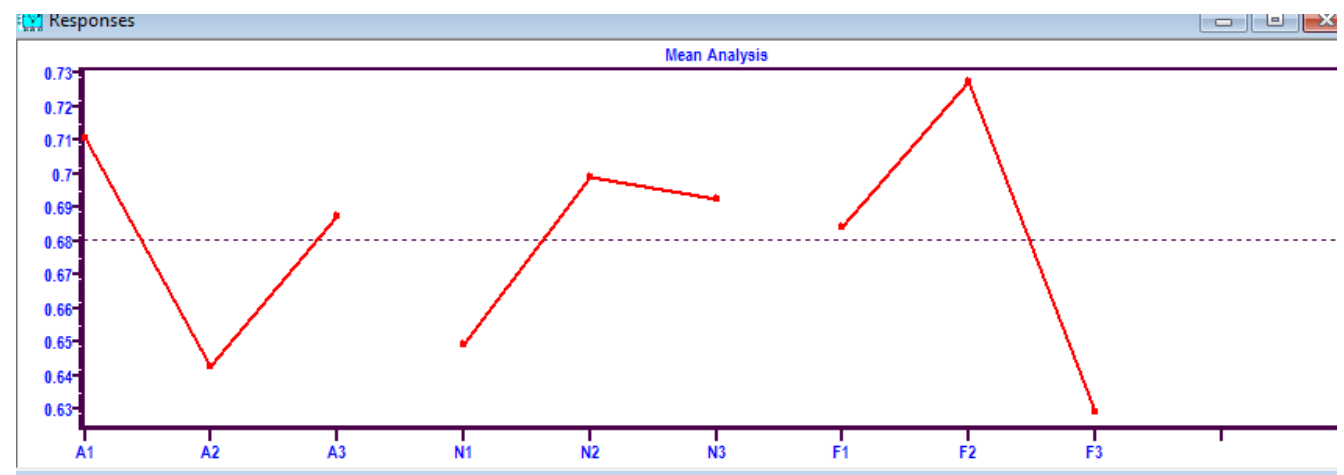

Figure 8. Response graph for grade values.

combination of control factors and to produce the best drilling output.

\section{Validation Test}

After completion of selection of optimal combination, it is necessary to predict and verify the improvement in the response parameters for the Carbon-Carbon composite material plate by drilling process with respect to the chosen initial control factor settings.

This validation test play vital role and last part of the parametric design. The predicted mean Grade is calculated by using the following formula,

$$
\tilde{\alpha}=\alpha_{\mathrm{m}}+\sum_{i=1}^{n}\left[\bar{\alpha}_{i}-\alpha_{m}\right]
$$

where, $\alpha$ is the average of grey relational grade, $\tilde{\alpha}$ is the mean grade corresponding to the $\mathrm{i}^{\text {th }}$ factor on the $\mathrm{j}^{\mathrm{et}}$ level and $\mathrm{n}$ is the no. of important factors that affect the multiple performance characteristics.

The GRG (predicted),

$$
\begin{aligned}
\tilde{\alpha}= & 0.681818998+(0.710682839-0.681818998)+ \\
& (0.69914322-0.681818998)+(0.727460035-0.681 \\
& 818998)=0.773648098
\end{aligned}
$$

Table 6, shows the comparison of the predicted and the actual drilling performance of the TiN coated solid carbide drill for multiple performance characteristic using their optimal cutting parameters.

The optimal level results of the confirmation experiment show that there is a reduction in delamination and improvement in quality of hole. It is evident clearly from the obtained results that the Response parameters in the 
carbon-carbon composite material drilling process are improved to a great extent through this method.

\section{Conclusions}

1. Experiments are conducted on a VMC100 CNC drilling machine to optimize the process control parameters.

2. It is clearly evident that the control factors, a drill bit point angle of $118^{\circ}$, a feed of $100 \mathrm{~mm} / \mathrm{min}$ and a spindle speed of $3000 \mathrm{rpm}$ of $22^{\text {nd }}$ experiment is the optimal combination to have a good drilling quality.

3. The predicted values were compared with the experimental values and a good agreement was found.

\section{Acknowledgement}

The authors express their gratitude to IIT, Anna University, CVRDE, Sathyabama University, Opus Precision ltd, and Micro Lab organizations of Chennai.

\section{References}

1. Wikipedia. Available from: http://en.wikipedia.org/wiki/ Drilling

2. Krishnasastry KV, Seshagirirao V, Kuravi A. Minimization of delamination factor in drilling of Reinforced CarbonCarbon (RCC) composite material by applying taguchi method. Int J Eng Adv Tech. 2013 Oct; 3(1):391-5. Available from: www. ijeat.org

3. Venkatarao R. Advanced modeling and optimization of manufacturing process. Springer.com; 2011.
4. Krishnasastry KV, Seshagiri Rao V. Parametric optimization of CFRC composite drilling with HSS drill by using GRA. International Journal of Innovative Research in Science. Engineering and Technology. 2013 Sep; 2(9):4368-78. Available from: www.ijrset.com

5. Krishnasastry KV, Dhanalakshmi S, Seshagirirao V, Palanikumar K. Characteristics of re-inforced carbon-carbon. IEEE Proc Int Conf on Frontiers in Automobile and Mechanical Engineering (FAME), 2010 Nov; p. 12-15.

6. Krishnasastry KV, Seshagirirao V. Carbon Fibre Reinforced Carbon (CFRC)-A special material. Proc Int Conf \& Exhibition on Pressure vessels and Piping; 2013 Feb; IGCAR, Kalpakam. 2013. C-086. p. 120.

7. Krishnasastry KV, Dhanalakshmi S, Seshagirirao V. CFRCA new millennium composite material. Proc Int Conf on Recent Advances in Mechanical Engineering (INCRAME), Dr. MGR univ. Chennai; 2011 Apr; p. 32-6.

8. Krishnasastry KV, Seshagirirao V. Application of grey relational analysis to determine the optimum drilling parameters of Rcc. International Journal of Research in Engineering \& Advanced Technology. 2013 Aug-Sept; 1(4):1-8. Available from: www.ijreat.org

9. George PM, Raghunath BK, Manocha LM, Warrier AM. EDM machining of carbon-carbon composite-a Taguchi approach. J Mater Process Tech. 2004 Jan; 145(1):66-71.

10. Ferreiraa JR, Coppinib NL, Levy Netoc F. Characteristics of carbon-carbon composite turning. J Mater Process Tech. 2001; 109:65-71.

11. Ross PJ. Taguchi techniques for quality engineering. New York: McGraw-Hill; 2004.

12. Koenig WR. Machining of fibre reinforced plastics. Ann CIRP. 34:537-48.

13. Khashaba UA. Delamination in drilling GFR-Thermoset composites. J Comps Struc. 2004; 63:329-38. 